\title{
Seasonal variations in the onset of retinal vein occlusion
}

\author{
Sohan Singh Hayreh, M Bridget Zimmerman, Patricia Podhajsky
}

\begin{abstract}
Seasonal variation in the development of retinal vein occlusion in 1003 consecutive patients with various types of retinal vein occlusion was studied prospectively from 1973 to 1990 . No seasonal variation in the onset of any type or combination of types of retinal vein occlusion was found. This refutes previous reports of such seasonal variation, which were based on small retrospective series.

(Brf Ophthalmol 1992; 76: 706-710)
\end{abstract}

Seasonal variation in the incidence of development of central retinal vein occlusion ${ }^{1}$ and 'retinal vein occlusion' has been reported during the past 5 years. Lavin and Dhillon, ${ }^{1}$ in a retrospective study of 105 central retinal vein occlusion (RVO) cases, found a significantly $(p<0.001)$ higher incidence during the 6 month period from September to February than for the 6 month period from March to August. They stated that variation in onset of central RVO was very similar to the variations in seasonal temperature. The seasonal variation in their study was similar for both ischaemic and nonischaemic central RVO. Peduzzi et $a l^{2}$ reported from a retrospective study of 127 Italian patients (from Modena, Italy) with 'retinal vein occlusion' that the incidence of RVO was significantly higher $(p<0.005)$ during the cold months $(42.5 \%)$ than during the warm $(26.7 \%)$ and intermediate $(30.7 \%)$ months, with no significant difference between two latter groups.

In the literature, there are also reports of higher incidence of myocardial infarction, cerebrovascular accidents, transient ischaemic attacks, and thrombosis during the winter than other seasons, attributed to the colder temperature. ${ }^{3-8}$

In view of these reports, we investigated seasonal variation in the development of various clinical and pathogenetic types of RVO. The study is based on our consecutive 1003 patients with various types of RVO, where the pertinent information was available, and who were studied prospectively from 1973 to 1990 . Our study showed no seasonal variation in the onset of any type of RVO individually or collectively.

\section{Materials and methods}

The source of information is a prospective, comprehensive study of patients with various types of RVO, who have been seen in the ocular vascular clinic of the University Hospitals and Clinics at Iowa City since 1973 . We analysed the data of 1003 patients with various types of RVO, seen consecutively in the clinic from 1973 until the end of 1990 .

\section{CLASSIFICATION OF RETINAL VEIN OCCLUSION}

To obtain scientifically valid information, it is essential to classify RVO into its different types. Our long-term studies on RVO have shown that in fact there are the following six distinct groups, each one of them with very different pathogenesis, clinical presentation, course, and management:

(A) Central retinal vein occlusion. Our experimental and clinical studies have demonstrated that this must be divided into the following two distinct entities ${ }^{10}$ : (i) non-ischaemic type (or venous stasis retinopathy); (ii) ischaemic type (or haemorrhagic retinopathy).

(B) Hemi-central retinal vein occlusion. This variant of central RVO was discovered by us, ${ }^{11}$ and, like central RVO, this type has two distinct subtypes: (i) non-ischaemic hemi-central RVO (or hemi-venous stasis retinopathy); (ii) ischaemic hemi-central RVO (or hemi-haemorrhagic retinopathy).

(C) Branch retinal vein occlusion. This requires to be further subdivided into two types: (i) major branch RVO involves one of the four major retinal branch veins; (ii) macular branch RVO involves one of the venous tributaries in the macular region.

Pathogenetically, central RVO and hemicentral RVO are identical in nature except that, in the former, the one trunk of the central retinal vein is occluded, while in the latter there are two anomalous trunks, only one of which is occluded in the optic nerve. Thus for purposes of data analysis, to determine characteristics in different permutations and combinations of RVO, we have grouped our patients into the following 13 categories:

I Central retinal vein occlusion group, comprising;

(1) All cases of this group combined.

(2) Non-ischaemic type only.

(3) Ischaemic type only.

II Hemi-central retinal vein occlusion group comprising:

(4) All cases combined. 
Table 1 Number of patients and episodes of retinal vein occlusion in its 13 categories defined in the text

\begin{tabular}{|c|c|c|c|}
\hline Type of retinal vein occlusion & Category & Number of patients ${ }^{\star}$ & Number of episodest \\
\hline \multicolumn{4}{|l|}{ Central retinal vein occlusion: } \\
\hline Total cases & 1 & 557 & 653 \\
\hline Non-ischaemic type & 2 & 439 . & 467 \\
\hline Ischaemic type & 3 & 179 & 186 \\
\hline \multicolumn{4}{|c|}{ Hemi-central retinal vein occlusion: } \\
\hline Total cases & 4 & 129 & 138 \\
\hline Non-ischaemic type & 5 & 96 & 97 \\
\hline Ischaemic type & 6 & 38 & 41 \\
\hline \multicolumn{4}{|c|}{ Central retinal vein occlusion +hemi-central retinal vein occlusion: } \\
\hline Total cases & 7 & 675 & 791 \\
\hline Non-ischaemic type & 8 & 531 & 564 \\
\hline Ischaemic type & 9 & 216 & 227 \\
\hline \multicolumn{4}{|l|}{ Branch retinal vein occlusion: } \\
\hline $\begin{array}{l}\text { Total cases } \\
\text { Major branch retinal vein }\end{array}$ & 10 & 345 & 373 \\
\hline \multirow{3}{*}{$\begin{array}{l}\text { Major branch retinal vein } \\
\text { occlusion } \\
\text { Macular branch retinal vein } \\
\text { occlusion }\end{array}$} & & & \\
\hline & 11 & 250 & 268 \\
\hline & 12 & 102 & 105 \\
\hline \multirow{2}{*}{$\begin{array}{l}\text { Total cases of retinal vein } \\
\text { occlusion }\end{array}$} & & 1003 & 1164 \\
\hline & 13 & 1003 & 1164 \\
\hline
\end{tabular}

^The total number of patients in the last line does not add up to the total for the six types of retinal vein occlusion (ie categories $2,3,5,6,11,12$ ) because some patients had more than one type of retinal vein occlusion. Similarly in categories $1,4,7$, and 10 the total patients do not add up to their respective two subtypes because some patients had more than one subtype of retinal vein occlusion

tSecond episode of the same type of retinal vein occlusion in the same eye was excluded in this analysis.
(5) Non-ischaemic only.

(6) Ischaemic only.

III Central and hemi-central retinal vein occlusions combined group (ie I+II above) because of their pathogenetic similarity:

(7) All cases combined.

(8) Non-ischaemic only (ie $2+5$ above).

(9) Ischaemic only (ie $3+6$ above).

IV Branch retinal vein occlusion group comprised:

(10) All cases in this group combined.

(11) Major branch RVO only.

(12) Macular branch RVO only.

V (13) All types of retinal vein occlusion combined (ie $2+3+5+6+11+12$ above).

As mentioned above, since central RVO and hemi-central RVO are pathogenetically similar in nature, in the data analyses we have also combined the two categories, to explore the subject further. In this data analysis, each episode of development of RVO is counted as an independent event. For example, an eye might have had major branch RVO and later on might have macular branch RVO - that would mean two episodes of RVO in that eye. Similarly, an eye may first develop non-ischaemic central RVO and that may later on change to ischaemic central RVO: that would be counted as two episodes of RVO in that eye. Several eyes developed a second episode of the same type of RVO, but that was not included in the analysis of episodes in this study. Table 1 gives details of number of patients and episodes of RVO in the 13 categories list above. The total number of patients in the last line in Table 1 does not add up to the total number of patients for the various types of RVO because several patients had more than one type of episode of RVO simultaneously or successively, in the same or in the fellow eye. Similarly, in Table 1, the total patients (that is, in categories 1, 4, 7 and 10) do not add up to their two respective subtypes because some patients had more than one subtype.

\section{INCLUSION CRITERIA FOR THE STUDY}

(1) We included in this study only those patients where a definite diagnosis of one of the six types of RVO could be made, based on the various inclusion criteria listed below.

(2) Since the time of onset of RVO is an important consideration in this study, every effort was made to establish this information as accurately as possible. It was almost invariably based on the history given by the patient. In some patients, however, retinal examination revealed a disparity between the history and examination - that is, the fundus findings indicated the RVO to be older than the history; such patients were excluded from the study. In a few non-symptomatic patients, duration of disease at first examination was assessed from the fundus findings, based on our experience of natural history of RVO in a large series over the past 25 years.

(3) All patients with inadequate information or doubtful diagnosis were excluded.

\section{DIAGNOSTIC CRITERIA FOR VARIOUS TYPES OF} RETINAL VEIN OCCLUSION

(A) Central retinal vein occlusion. This was classified as non-ischaemic or ischaemic, based on the combined information obtained from visual acuity, visual fields (done with a Goldmann

Table 2 Seasonal variation: result of goodness-of-fit tests

\begin{tabular}{|c|c|c|c|c|c|c|c|c|c|}
\hline \multirow[b]{2}{*}{ Type of retinal vein occlusion } & \multirow[b]{2}{*}{$\begin{array}{l}\text { Sample } \\
\text { size }\end{array}$} & \multicolumn{2}{|l|}{ Month } & \multicolumn{2}{|l|}{ Quarter } & \multicolumn{2}{|l|}{ Season } & \multicolumn{2}{|c|}{ Temperature } \\
\hline & & $\begin{array}{l}\chi^{2} \\
(d f=11)\end{array}$ & p value & $\begin{array}{l}\chi^{2} \\
(d f=3)\end{array}$ & p value & $\begin{array}{l}\chi^{2} \\
(d f=3)\end{array}$ & p value & $\begin{array}{l}\chi^{2} \\
(d f=2)\end{array}$ & pvalue \\
\hline \multicolumn{10}{|l|}{ Central retinal vein occlusion: } \\
\hline $\begin{array}{l}\text { All patients } \\
\text { (a) Non-ischaemic type } \\
\text { (b) Ischaemic type }\end{array}$ & $\begin{array}{l}653 \\
467 \\
186\end{array}$ & $\begin{array}{r}11 \cdot 280 \\
7 \cdot 570 \\
18 \cdot 955\end{array}$ & $\begin{array}{l}0.4201 \\
0.7512 \\
0.0619\end{array}$ & $\begin{array}{l}3 \cdot 752 \\
4 \cdot 424 \\
0 \cdot 586\end{array}$ & $\begin{array}{l}0.2895 \\
0.2191 \\
0.8995\end{array}$ & $\begin{array}{l}1.393 \\
1.252 \\
0.654\end{array}$ & $\begin{array}{l}0.7071 \\
0 \cdot 7405 \\
0 \cdot 8840\end{array}$ & $\begin{array}{l}0.626 \\
0.086 \\
2.923\end{array}$ & $\begin{array}{l}0.7313 \\
0.9577 \\
0.2319\end{array}$ \\
\hline \multicolumn{10}{|c|}{$\begin{array}{l}\text { (b) Ischaemic type } \\
\text { Hemi-central retinal vein occlusion: }\end{array}$} \\
\hline $\begin{array}{l}\text { All patients } \\
\text { (a) Non-ischaemic type } \\
\text { (b) Ischaemic type }\end{array}$ & $\begin{array}{r}138 \\
97 \\
41\end{array}$ & $\begin{array}{r}10 \cdot 276 \\
9 \cdot 180 \\
7 \cdot 838\end{array}$ & $\begin{array}{l}0.5057 \\
0.6053 \\
0.7278\end{array}$ & $\begin{array}{l}4 \cdot 406 \\
4 \cdot 284 \\
1 \cdot 847\end{array}$ & $\begin{array}{l}0 \cdot 2208 \\
0 \cdot 2324 \\
0 \cdot 6048\end{array}$ & $\begin{array}{l}3 \cdot 170 \\
2 \cdot 441 \\
2 \cdot 194\end{array}$ & $\begin{array}{l}0.3662 \\
0.4860 \\
0.5330\end{array}$ & $\begin{array}{l}2 \cdot 783 \\
1.378 \\
1.973\end{array}$ & $\begin{array}{l}0.2487 \\
0.5020 \\
0.3728\end{array}$ \\
\hline \multicolumn{10}{|c|}{ Central retinal vein occlusion +hemi central retinal vein occlusion: } \\
\hline $\begin{array}{l}\text { All patients } \\
\text { (a) Non-ischaemic type } \\
\text { (b) Ischaemic type }\end{array}$ & $\begin{array}{l}791 \\
564 \\
227\end{array}$ & $\begin{array}{r}11 \cdot 116 \\
7 \cdot 720 \\
15 \cdot 266\end{array}$ & $\begin{array}{l}0.4336 \\
0 \cdot 7382 \\
0.1706\end{array}$ & $\begin{array}{l}5 \cdot 067 \\
5 \cdot 822 \\
1 \cdot 232\end{array}$ & $\begin{array}{l}0 \cdot 1670 \\
0 \cdot 1206 \\
0 \cdot 7454\end{array}$ & $\begin{array}{l}2 \cdot 366 \\
1.887 \\
0.623\end{array}$ & $\begin{array}{l}0 \cdot 5001 \\
0 \cdot 5961 \\
0 \cdot 8911\end{array}$ & $\begin{array}{l}0.975 \\
0.051 \\
2.529\end{array}$ & $\begin{array}{l}0.6143 \\
0.9750 \\
0.2824\end{array}$ \\
\hline \multirow{2}{*}{$\begin{array}{l}\text { Branch retinal vein occlusion: } \\
\text { All patients } \\
\text { (a) Major type } \\
\text { (b) Macular type } \\
\text { All types of retinal vein } \\
\text { occlusion: }\end{array}$} & $\begin{array}{l}373 \\
268 \\
105\end{array}$ & $\begin{array}{l}12 \cdot 401 \\
12 \cdot 774 \\
17 \cdot 439\end{array}$ & $\begin{array}{l}0.3343 \\
0.3083 \\
0.0955\end{array}$ & $\begin{array}{l}3 \cdot 290 \\
2 \cdot 342 \\
5 \cdot 828\end{array}$ & $\begin{array}{l}0 \cdot 3490 \\
0 \cdot 5044 \\
0 \cdot 1203\end{array}$ & $\begin{array}{l}1.876 \\
2.552 \\
0.854\end{array}$ & $\begin{array}{l}0.5986 \\
0.4660 \\
0.8365\end{array}$ & $\begin{array}{l}3.357 \\
1.571 \\
2.363\end{array}$ & $\begin{array}{l}0.1866 \\
0.4558 \\
0.3069\end{array}$ \\
\hline & 1164 & $11 \cdot 702$ & 0.3865 & $5 \cdot 768$ & $0 \cdot 1235$ & $3 \cdot 733$ & $0 \cdot 2918$ & $3 \cdot 125$ & $0 \cdot 2096$ \\
\hline
\end{tabular}

$\star$ Number of episodes of retinal vein occlusion. 


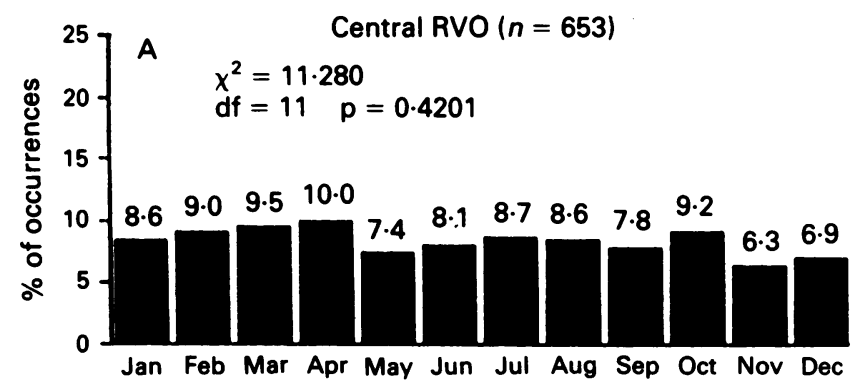

Jan Feb Mar Apr May Jun Jul Aug Sep Oct Nov Dec

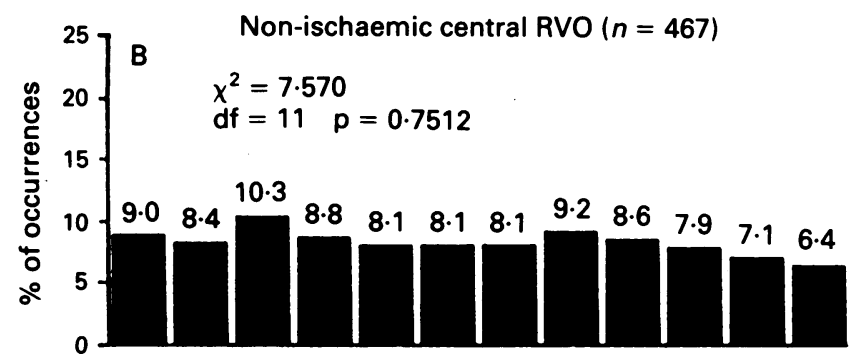

Jan Feb Mar Apr May Jun Jul Aug Sep Oct Nov Dec
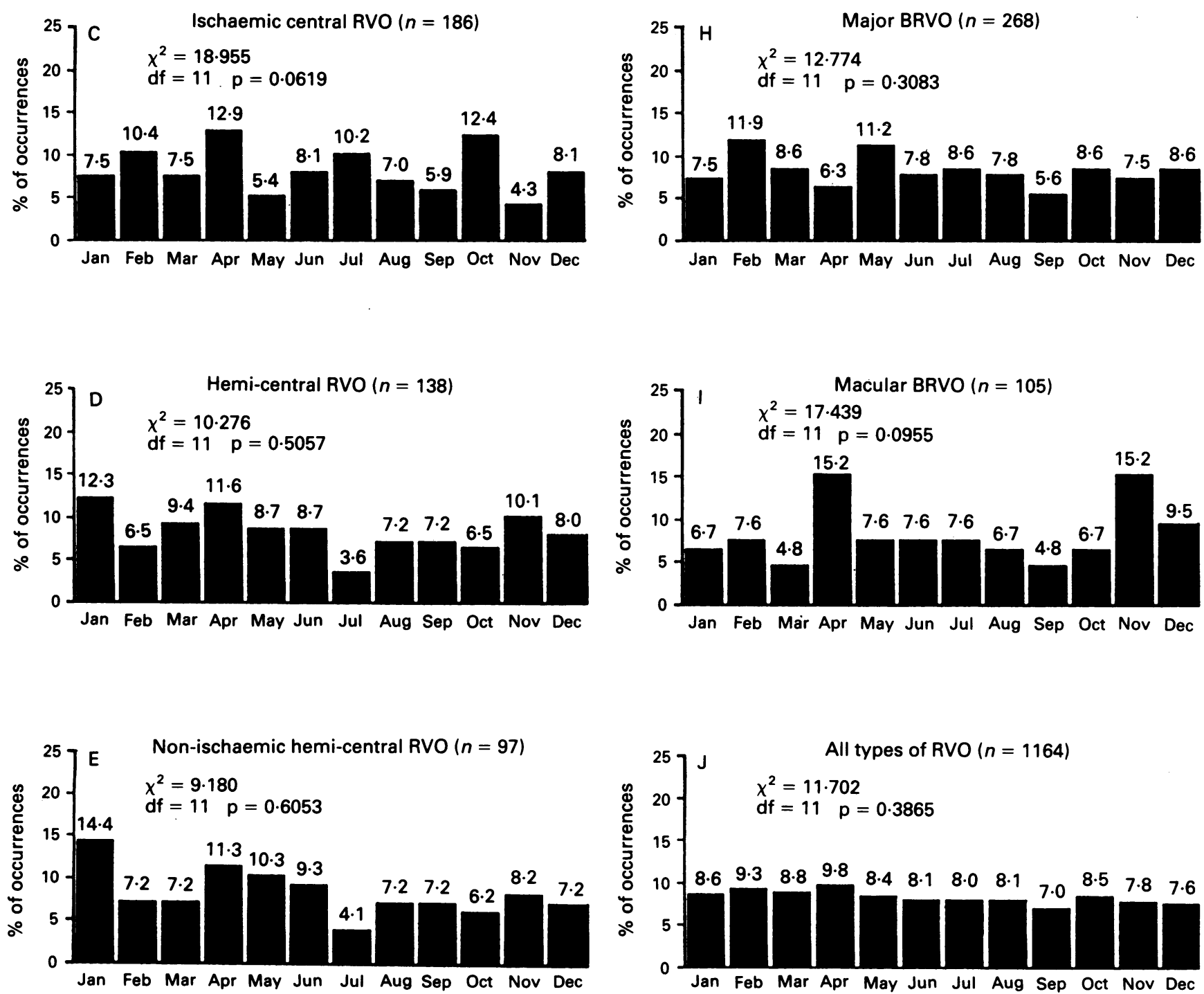
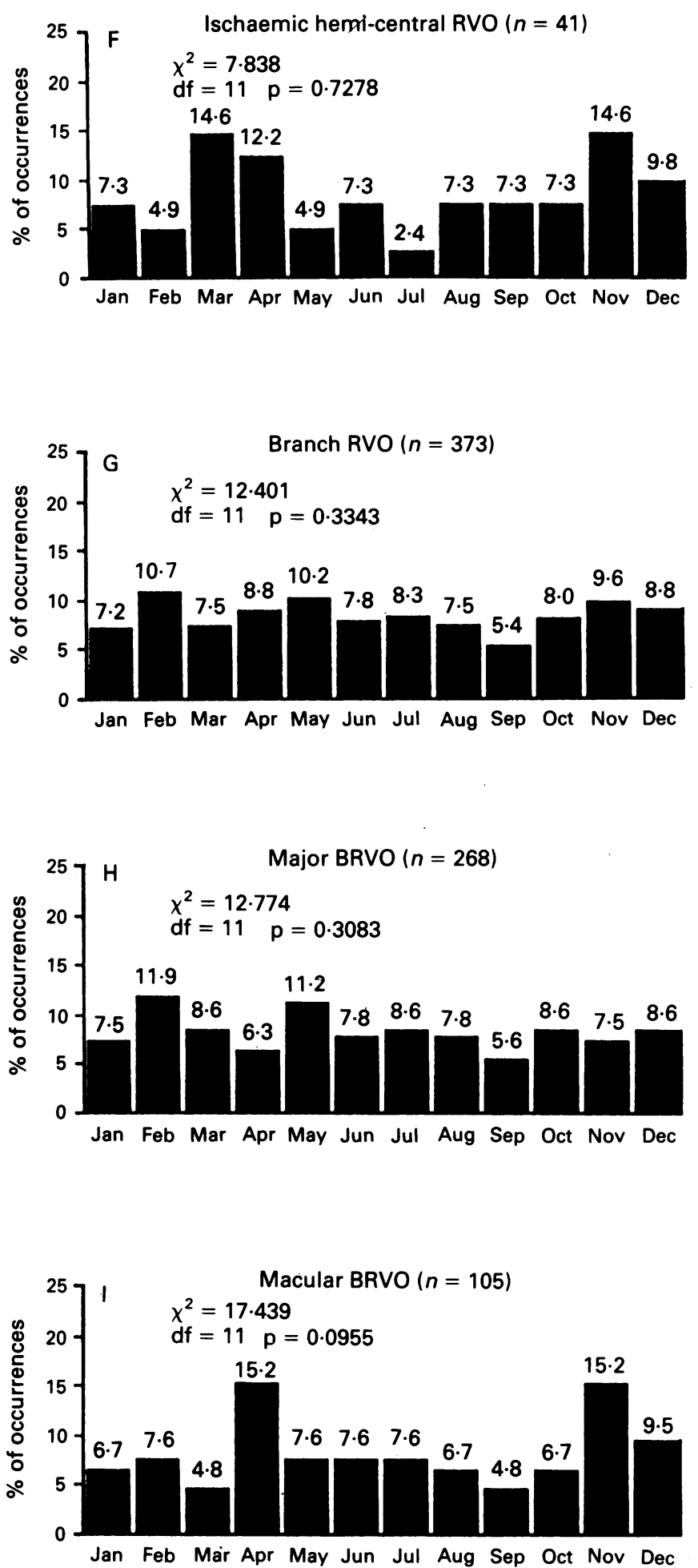

Jan Feb Mar Apr May Jun Jul Aug Sep Oct Nov Dec

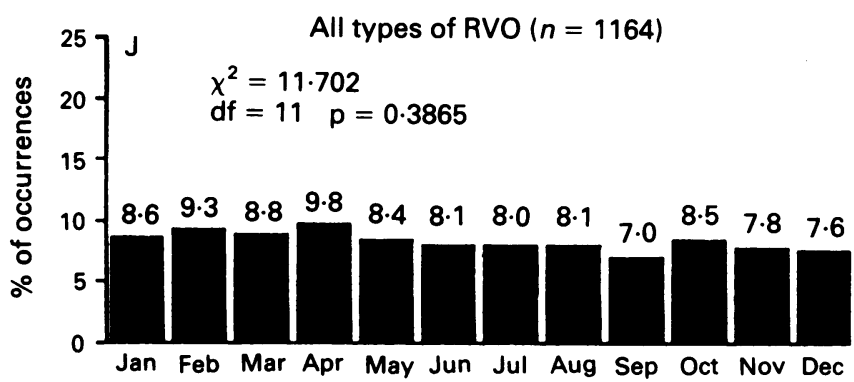

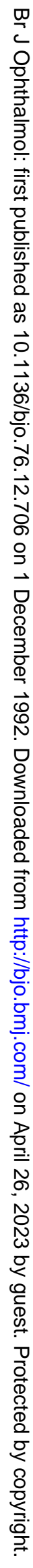

Figure 1 The distribution of occurrences of onset of retinal vein occlusion $(R V O)$ of various types ( $A$ to $\mathcal{F}$, see Table 1) by calendar months with $\chi^{2}$ of goodness-of-fit test statistic and corresponding p value. 
perimeter), relative afferent pupillary defect, electroretinopathy, ophthalmoscopy and fluorescein fundus angiography, as discussed elsewhere. ${ }^{910}$ We made every attempt to exclude other retinopathies mimicking central RVO.

(B) Hemi-central retinal vein occlusion. We have described criteria to define non-ischaemic and ischaemic varieties of this type of RVO elsewhere."

(C) Branch retinal vein occlusion. In eyes with 'major branch retinal vein occlusion' one of the four major branch retinal veins had to be occluded near, or rarely at the optic disc. In eyes with 'macular branch retinal vein occlusion' the macular venule had to be occluded.

In some cases, follow-up information provided a definite diagnosis if it was doubtful at the initial visit.

\section{DATA ANALYSIS}

For each category of RVO the null hypothesis tested was:

Ho: there is no seasonal variation in onset time, against the alternative hypothesis:

$H a$ : there is seasonal variation in onset time.

Seasonal variation in the onset of various types of RVO were examined in four different ways.

(1) By calendar month.

(2) By quarters of the year:

(a) January to March

(b) April to June

(c) July to September

(d) October to December.

(3) By seasons of the year:

(a) Winter: December to February

(b) Spring: March to May

(c) Summer: June to August

(d) Fall: September to November

(4) By temperature of the season in this part of the country:

(a) Cold: November to March (average: High

-1 to $+8^{\circ} \mathrm{C}$ and low -1 to $-11^{\circ} \mathrm{C}$ ).

(b) Mild: April, May, October (average: high 16 to $22^{\circ} \mathrm{C}$ and low 4 to $11^{\circ} \mathrm{C}$ ).

(c) Hot: June to September (average: high 24 to $30^{\circ} \mathrm{C}$ and low 13 to $18^{\circ} \mathrm{C}$ ).

Each of the four time divisions was examined in the 13 categories of RVO described above. Each disease category and time group was first analysed without considering age or gender. Subsequent analyses tested for association between seasonal groups and age and sex. The statistical test used to test the hypothesis of no seasonal variation was the $\chi^{2}$ goodness-of-fit test. If there is no seasonal variation in onset of disease then we would expect an equal rate of occurrence. The goodness-of-fit test ${ }^{12}$ determines if there are significant statistical departures from expected values. A $p$ value of 0.05 was used to determine significant differences. In performing these statistical tests, when both eyes were involved, each occurrence in each eye was considered as an independent event. Occurrence of any of the six types of RVO in the same patient in the same eye was also considered as an independent event. When a patient had multiple episodes of the same type of RVO in the same eye, only the first episode was included in the analysis.

Analysis of the data using log-linear model was also done. The log-linear model included sex, age at onset, and time of onset (using the categories defined above for seasonal variation) as the factors in the model. The patients were divided into three age groups, in accordance with the criteria used by the US National Center for Health Statistics, US Public Health Services ${ }^{13}$ : young (less than 45 years old), middle-aged (45 to 64 years old), and elderly (65 or older). Interaction of time of onset with sex and age were examined to determine if sex of patient and/or age at onset should be considered when testing for seasonal variation in onset tme.

\section{Results}

The log-linear model analysis showed that time of onset showed no significant association with sex and age at onset. Thus, seasonal variation was tested over males and females and all age groups combined.

Table 2 summarises the results of the $\chi^{2}$ goodness-of-fit test. Figure 1 shows the distribution of occurrences of onset of RVO of various types (A to $\mathrm{J}$ ) by calendar months with the $\chi^{2}$ goodness-of-fit test statistic and corresponding $p$ value. For each of the different types of RVO, the test results show no significant departure from the assumed model of equal rate of occurrence of RVO. The other analyses, by quarters of the year, by seasons of the year, and by temperature, showed similar results (Table 2). The $\mathrm{p}$ values obtained from the $\chi^{2}$ goodness-of-fit tests ranged from $p=0 \cdot 1203$ to $p=0.9750$ (Table 2).

\section{Discussion}

Our study does not bear out the finding of seasonal variation in the development of RVO reported in two previous studies. ${ }^{12}$ One study was from London and based on retrospective review of information of 105 cases of central RVO.' The other report was from Modena, Italy and based on a retrospective study of 127 patients with 'retinal vein occlusion" - the authors give no information about the number of various types of RVO included in their study. Lavin and Dhillon ${ }^{1}$ argued that a seasonal incidence of central RVO may be comparable with thrombotic lesions in other organs, because myocardial infarctions and cerebrovascular accidents are more frequent in winter than other seasons and show close correlations with temperature,,$^{3-8}$ and that cold temperature is associated with an increased risk of thrombosis. ${ }^{5}$

It could conceivably be argued that differences in living conditions in Britain and Italy on the one hand, and the midwestern United States on the other, could be responsible for our not finding any seasonal variation. Such a hypothesis is, however, hard to maintain. The winter temperatures in Iowa are much lower (average: high -1 to $+8^{\circ} \mathrm{C}$ and low -1 to $-11^{\circ} \mathrm{C}$ ), for much longer, than in London (England) (average: high 7 to $11^{\circ} \mathrm{C}$ and low 2 to $8^{\circ} \mathrm{C}$ ) or Modena (Italy) (average: high 9 to $14^{\circ} \mathrm{C}$ and low 
2 to $8^{\circ} \mathrm{C}$ ). Buildings and cars which are wellheated during winter are almost universal in Iowa compared with the other two countries, so that the indoor temperature in Iowa is likely to be much warmer than in Britain and Italy during winter. It might be just possible to claim that this difference is responsible for our not seeing any seasonal variation. This possibility has also been suggested by a study indicating that the lowest seasonal variation occurs in countries with very cold winters (for example, Scandinavia) which would imply that insulation and indoor heating may be preventive factors. ${ }^{14}$ However, it is hard to find much support for this argument. A British study found that elderly people living in centrally heated warden-controlled accommodation showed similar seasonal variation in mortality rates to those living in their own (noncentrally heated) homes. ${ }^{15}$ Also, one of us (SSH) can attest from years of residence in Britain and Iowa that the British and other Europeans dress much more warmly at home than Iowans do, so that the effect of central heating in Iowa is counterbalanced by the warmer clothes in Europe. Moreover, the hypothetical beneficial effects of central heating in Iowa would be counteracted by the extreme cold often experienced when a person goes outdoors during winter, whether of necessity or for recreation, as was also pointed out by Keatinge. ${ }^{15}$ Further, Keatinge $e t a l^{16}$ in their study in England and Wales found that with an increase in proportion of households with central heating from $13 \%$ to $69 \%$ from 1964 to 1984 , there was no significant decrease in excess winter mortality from coronary and cerebrovascular disease. The study by Stout and Crawford ${ }^{8}$ from Belfast, Northern Ireland, suggested that central heating may not greatly increase minimum indoor temperature or influence core body temperature at all. The centrally heated accommodation in Iowa therefore cannot explain the marked disparity between our results and those of the other two studies.

A more likely explanation of the disparity of results betwen ours and the two European studies lies in their relatively small samples and the retrospective nature of their data collection. It is generally well-accepted that information retrieved retrospectively from old records, gathered from routine visits to a busy clinic, cannot be relied upon to produce scientifically valid results. Our study, on the other hand, was a well planned, prospective study whose data can be confidently relied upon.

\section{CONCLUSIONS}

Our prospective study on a large sample of different types of RVO showed no seasonal variation in their development.

This work was supported by grant EY-1151 from the US Nationa Institutes of Health, and in part by unrestricted grants from Research to Prevent Blindness, Inc, New York, and from Alcon Research Institute, Fort Worth, Texas, USA.

1 Lavin MJ, Dhillon BJ. Cyclic variation in onset of centra retinal vein occlusion. Brf Ophthalmol 1987; 71: 18-20

2 Peduzzi M, Debbia A, Guerrieri F, Torlai F, DeFranceso G Seasonal variations in incidence of retinal vein occlusion Poster-abstract from Program of Club Jules Gonin XVI Meeting 4-8 September, 1988, Bruges, pl42.

3 Bull GM. Meteorological correlates with myocardial and cerebral infarction and respiratory disease. Brf Prevent Soc Med 1973; 27: 108-13.

4 Bull GM, Morton J. Environment, temperature and death rates. Age Ageing 1978; 7: 210-24.

5 Bull GM, Brozovic M, Chakrabarti R, Meade TW, Morton J, North WRS, et al. Relationship of air temperature to various chemical, haematological and haemostatic variables. $\mathcal{f}$ Clin Pathol 1979; 32: 16-20.

6 Clark CV. Seasonal variation in incidence of brachial and femoral emboli. $B M \mathcal{F} 1983 ; 287$ : 1109.

7 Fersini C, Manfredini R, Manfredini F, Balboni G, Fersini G Chronobiologic aspects of recurrent transient ischemic attack. In: Pauly JE, Scheving LE, eds. Advances in chronobiology, Part B. New York: Alan R Liss, 1987:
167-71.

8 Stout RW, Crawford V. Seasonal variations in fibrinogen concentrations among elderly people. Lancet 1991; 338: concen.

9 Hayreh SS. Classification of central retinal vein occlusion. Ophthalmology 1983; 90: 458-74.

10 Hayreh SS, Klugman MR, Beri M, Kimura AE, Podhajsky $P$ Differentiation of ischemic from non-ischemic central retinal vein occlusion during the early acute phase. Graefes Arch Klin Exp Ophthalmol 1990; 228: 201-17.

11 Hayreh SS, Hayreh MS. Hemi-central retinal vein occlusion. Pathogenesis, clinical features, and natural history. Arch Ophthalmol 1980; 98: 1600-9.

12 Haberman SJ. Analysis of qualitative data, vol 1, New York: Academic Press, 1978: 45

13 Vital and Health Statistics Current Estimates from the National Health Interview Survey, 1989. Series 10 and 11, Public Health Services, National Center for Health Statistics. Hyattsville, MD, 1990.

14 McKee CM. Deaths in winter: can Britain learn from Europe? Eur $\mathcal{F}$ Epidemiol 1989; 5: 178-82.

15 Keatinge WR. Seasonal mortality among elderly people with unrestricted home heating. $B M \mathcal{F} 1986 ; 293: 732-3$.

16 Keatinge WR, Coleshaw SR, Holmes J. Changes in seasonal mortalities with improvement in home heating in England and Wales from 1964 to 1984 . Int $\mathcal{F}$ Biometeorol 1989; 33: 716. 